\title{
A Segregação dos Jovens em Paris*
}

\section{Edmond Préteceille}

Pesquisador emérito do Centre National de la Recherche Scientifique (CNRS) na Sciences Po; membro do Observatoire Sociologique du Changement e professor de sociologia urbana.

E-mail: edmond.preteceille@sciences-po.fr

\begin{abstract}
A situação de moradia dos jovens tem mais importância para eles do que para os pais, com quem moram. Por um lado, sua mobilidade mais reduzida - ainda mais reduzida quanto mais jovens forem faz com que fiquem muito dependentes dos bens e serviços disponíveis no bairro, em especial dos equipamentos e serviços públicos, da presença e qualidade desses equipamentos e serviços, sendo portanto diretamente atingidos pelas desigualdades urbanas que caracterizam as diversas situações de moradia. Por outro lado, pelo mesmo motivo, a construção de sua sociabilidade, elemento maior dessa fase da vida, apoia-se muito nas relações de vizinhança, em especial na influência do grupo de pares, na escola e no bairro. Essas duas dimensões das desigualdades urbanas e da sociabilidade local articulam-se estreitamente com a da segregação residencial, definida como distribuição desigual dos grupos sociais, segundo os diferentes espaços de uma cidade: a segregação distribui os grupos nos espaços desiguais em recursos, ela os distribui ao mesmo tempo nos espaços em que a configuração dos grupos em copresença, que contribui para definir as condições da sociabilidade local, é variável.
\end{abstract}

\footnotetext{
* Este artigo foi, originariamente, apresentado no Seminário "Juventude, Desigualdades e o Futuro do Rio de Janeiro", realizado na Casa de Rui Barbosa, em junho de 2011, como parte das atividades do Programa de Apoio a Núcleos de Excelência (Pronex), sediado no IESP-UERJ. [A tradução do original em francês, "La Ségrégation des Jeunes à Paris" é de Estela Abreu].
}

DADOS - Revista de Ciências Sociais, Rio de Janeiro, vol. 55, n-2, 2012, pp. 301 a 325. 
A segregação dos jovens, na literatura sociológica francesa, foi abordada sobretudo do ponto de vista das situações de forte segregação, associadas especialmente às interrogações quanto ao desvio e à delinquência nas práticas dos jovens (Kokoreff, 1996); são, aliás, os jovens que estão no centro das discussões sociológicas e político-midiáticas sobre esses bairros, sendo vistos como vítimas do fracasso escolar, do desemprego ou como atores da delinquência e das revoltas. Muitos trabalhos sobre esses bairros, de Lepoutre (1997) a Lapeyronnie (2008), mostraram a importância do grupo de pares nas práticas dos jovens, bem como, de modo mais geral, da composição social desses bairros e das relações sociais aí contraídas entre os moradores e as instituições. A importância dos efeitos das desigualdades urbanas talvez tenha sido menos destacada; assim, em relação à escola, é a influência da composição da população dos alunos que foi quase sempre apontada, ao passo que Oberti (2007) mostrou a importância da desigualdade de oferta escolar, ao contrário do caráter teoricamente igualitarista da escola pública, pilar do "modelo republicano" de tipo francês.

Se o estudo dos efeitos das desigualdades urbanas nos bairros em dificuldade merece, a nosso ver, mais atenção, parece também que a análise da segregação não pode ser reduzida à dos espaços mais pobres, dos "bairros de exclusão"; mesmo para compreender a formação deles, o estudo das condições urbanas referentes às práticas sociais dos jovens deveria considerar a gama das diferentes situações residenciais que condicionam sua experiência urbana. Se a mídia pratica diariamente uma leitura dualista caricatural da cidade, opondo os "jovens da periferia" - expressão que designa, implicitamente, os jovens de origem magrebina ou africana morando em conjuntos sociais deficientes, com fracasso escolar e comportamento inquietante, delinquentes ou participantes do narcotráfico - à população da cidade "normal", é indispensável que os sociólogos desconstruam essa caricatura opondo uma leitura mais atenta à diversidade dos bairros periféricos e dos jovens desses bairros. Uma das intenções deste artigo é fornecer elementos para perceber a diversidade das situações urbanas e os perfis de seus jovens.

Se a segregação tem consequências mais importantes para os jovens, ela está em geral marcada pela que existe em relação à população adulta, da qual é mais fácil descrever os traços que ajudam a localizar os grupos sociais: características socioeconômicas, para as quais a categoria socioprofissional (Desrosières e Thévenot, 1988) é a variável mais 
utilizada na França; e origens nacionais que permitem, na França, situar a segregação etnorracial. Entretanto, diferentes pesquisas de campo levam-nos a pensar que, para os jovens, a segregação pode ter características que vão além daquelas sofridas por seus pais. Vejamos dois exemplos.

O primeiro refere-se a um bairro na zona nordeste da cidade de Paris (municipalidade cujo território é mais ou menos delineado pelo bulevar periférico). Se a análise estatística (Préteceille, 2003; 2006) mostra um perfil socioeconômico variado, com executivos e profissionais de nível superior, profissões intermediárias, empregados e operários, o estudo da população em idade escolar revela uma distribuição mais bimodal: de um lado, crianças de categorias médio-superiores; de outro, de categorias populares com pouca qualificação. A explicação do contraste está nos processos de povoamento e nas modalidades de acesso à moradia no bairro: a alta dos preços imobiliários faz com que apenas as categorias médio-superiores possam hoje residir em apartamentos com espaço suficiente para criar os filhos; as famílias de nível médio ou popular já não podem aspirar a tais domicílios, e quem lá reside são jovens sem filhos ou pessoas idosas que vivem no bairro há muito tempo; enfim, a forte presença de crianças das camadas populares menos qualificadas se explica pela existência de muitos conjuntos habitacionais em que essas categorias estão altamente representadas.

O segundo exemplo refere-se a um bairro de periferia cuja análise estatística mostra, ao contrário do anterior, que se trata de local bastante homogêneo no plano socioeconômico - povoado essencialmente de empregados e operários - mas bastante diverso no plano das origens nacionais, sendo, no entanto, os imigrados nitidamente minoritários. Também nesse caso, o estudo da população escolar (ver artigo de M. Oberti a ser publicado nesta Revista) mostra um perfil diferente, marcado por nítida maioria de alunos de origem estrangeira. Essa diferença não se explica por um problema de tratamento estatístico - foi possível caracterizar a origem imigrada das crianças por meio da origem dos pais quando elas residem com a própria família -, tampouco por uma opção de rejeição escolar da parte dos pais não imigrados - estratégias de rejeição são bem menos frequentes nos meios populares (Oberti, 2007; Van Zanten, 2009). A explicação é essencialmente demográfica: os casais não imigrados são em média mais idosos e, por isso, têm menos filhos em idade escolar; e a taxa de fecundidade das mulhe- 
res imigradas, sobretudo das recém-chegadas, é mais elevada que a das não imigradas.

Esses dois exemplos mostram as duas principais causas que levam a pensar que a segregação dos jovens tem características específicas, podendo induzir a uma inflexão significativa da segregação dos adultos; por um lado, os casais com filhos não têm, em condições sociais semelhantes, a mesma localização que os casais sem filhos; por outro, os casais com filhos não têm as mesmas características sociais que os outros. Sobre esse último ponto, as diferenças atuais são sobretudo função das origens, imigradas ou não, e pouco das diferenças socioeconômicas, pois as diferenças entre categorias socioprofissionais em relação ao número de filhos, que outrora se apresentavam na clássica curva em $U$, praticamente desapareceram na França.

São essas duas dimensões da segregação específica dos jovens que, neste artigo, vamos examinar no caso da metrópole parisiense ${ }^{1}$.

\section{SEGREGAÇÃO SOCIOECONÔMICA E LOCALIZAÇÃO RESIDENCIAL DOS JOVENS}

A localização residencial dos casais com filhos se distingue daquela dos casais sem filhos, em determinada categoria socioprofissional, como se vê nos trabalhos dos demógrafos sobre os efeitos residenciais do ciclo de vida (Le Bras e Chesnais, 1976; Bonvalet, 1994). Os casais com filhos têm necessidade de espaços maiores, com renda ou despesa igual para a moradia; são, portanto, obrigados a localizações menos dispendiosas e, assim, menos centrais. Os casais com filhos pequenos são mais jovens e, por isso, em início de carreira, com salários menores em cada categoria profissional. Além disso, alguns desses casais preferem casa com jardim para criar os filhos pequenos.

É preciso, contudo, ponderar sobre esse último ponto, pois, por causa da elevada taxa de atividade feminina na França e pela cultura que conta menos com a família do que na Itália ou na Espanha e mais com os serviços coletivos para cuidar das crianças, uma parte das famílias pode preferir uma moradia menor, mas em bairro que ofereça mais serviços coletivos, como creches. No entanto, é apenas uma nuança ou moderação dos efeitos dos fatores indicados anteriormente, que contribuem para explicar por que, como se vê nos dois mapas a seguir, a proporção dos jovens na população local é tanto maior quanto mais periférica for a localização residencial. 


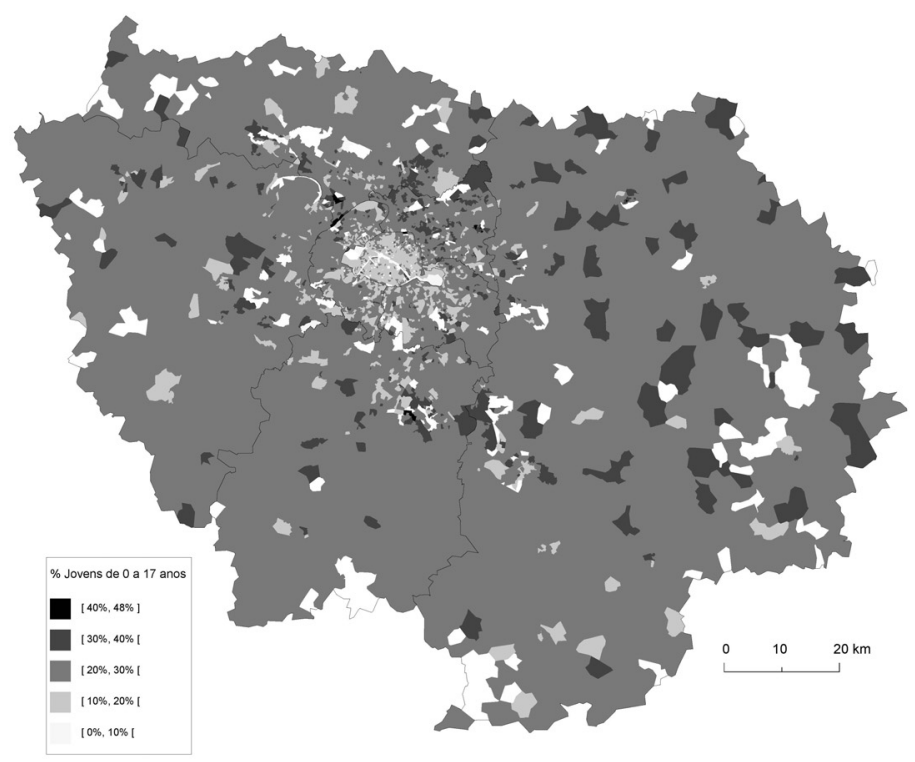

Fonte: INSEE, Censo da População de 2007.

Um dos principais efeitos dessa localização periférica dos jovens é ficarem eles longe dos recursos urbanos, dos equipamentos e serviços coletivos, que estão em geral bem mais presentes nas zonas centrais da metrópole e se reduzem nas regiões afastadas do centro, onde a urbanização é mais recente. Isso é bastante claro no que se refere às creches - a ponto de se chegar a uma correlação negativa entre o número de vagas de creche por criança em idade de frequentá-las e a proporção dessas crianças na população local! -, aos equipamentos culturais e aos serviços de saúde, públicos e particulares (Préteceille, 2001). É claro que essa distância dos jovens em relação aos recursos urbanos é, em média, maior quando pertencem a categorias sociais mais modestas. Ao con- 
trário, os jovens das categorias superiores ou médio-superiores que podem residir em Paris ou na parte interior do primeiro anel da periferia - com exceção dos municípios mais populares de Seine-SaintDenis, que empobreceram - gozam de ambiente urbano bem-provido de equipamentos e serviços.

A presença de jovens dessas categorias populares é hoje fraca em Paris, a não ser nos distritos da zona nordeste e nos mais periféricos, onde a existência de muitos conjuntos habitacionais lhes possibilita morar. Isso é ainda mais nítido nos municípios bem-equipados do primeiro anel da periferia, que, outrora, constituíam o "anel vermelho", onde municípios de esquerda desenvolveram não só uma série de conjuntos habitacionais, mas também importantes equipamentos públicos.

Se a presença de conjuntos habitacionais nas localizações relativamente centrais confronta parcialmente a hierarquização dos espaços dos jovens em função do meio social, é claro que esse efeito tende a diminuir com o tempo. O território da cidade de Paris e dos municípios dos subúrbios mais próximos está praticamente quase todo urbanizado e já não pode se tornar mais denso. Por tais motivos, por questões políticas $^{2}$ e também por causa do preço dos terrenos, a maior parte da produção de habitações sociais ocorre hoje no segundo anel da periferia ${ }^{3}$. Assim, entre 1999 e 2007, em 17.165 novas famílias residindo em HLM (Habitação de aluguel moderado), 12.544 estão no segundo anel, 3.977 em Seine-Saint-Denis e no Val-de-Marne, 388 em Hauts-de-Seine e 256 em Paris.

Ao mesmo tempo, houve um aumento muito grande no preço dos imóveis e dos aluguéis no centro da metrópole. Em dez anos, os preços das moradias subiram mais que o dobro em toda a França: atingiram no 20 trimestre de 2011 um patamar de 214, considerando-se 100 como base no $4^{\circ}$ trimestre de $2000^{4}$; para o conjunto da metrópole parisiense, esse índice chegou a 229 e, para Paris, a 274! Como a inflação para o mesmo período foi limitada (o índice dos preços atingiu 118 em 2010 para uma base 100 em 2000), tal aumento quase tríplice torna uma residência em Paris inacessível não apenas às classes populares, com exceção da habitação social, mas também às classes médias, e até mesmo a algumas médio-superiores, sobretudo quando estão em início de carreira profissional e necessitam de mais espaço para os filhos.

No esquema habitual das escolhas de localização em função do ciclo de vida, viu-se que os casais tendiam a voltar para localizações mais cen- 
trais quando os filhos cresciam, pois a busca de proximidade de uma boa escola superava o gosto pela natureza. Os estudos de sociologia da educação mostraram a preocupação dos pais e o investimento crescente deles no êxito escolar dos filhos, e isso em todas as categorias sociais, fato que antes era só característico das categorias médias. Parece que hoje a proximidade de estabelecimentos escolares de qualidade se torna fator de crescente importância nas escolhas residenciais. Contudo, parece também que o nível dos preços imobiliários e as fortes tensões no mercado habitacional fazem com que somente os pais das categorias abastadas, médio-superiores ou superiores possam de fato utilizar essas estratégias residenciais. A considerável alta dos preços na parte central da metrópole, onde se situam quase todos os colégios de prestígio, concentra ainda mais esse tipo de mobilidade residencial da periferia para o centro só para as categorias mais favorecidas. Para os moradores dos HLM, esse tipo de mobilidade é quase impossível, pois, além de os HLM do centro urbano terem uma taxa de rotatividade muito fraca, a atribuição dos HLM ocorre essencialmente dentro da mesma entidade administrativa; o locatário de uma instituição municipal só pode mudar de moradia no mesmo município.

Para explicitar o efeito dessas imposições, seria necessário analisar as mudanças da população jovem de acordo com a categoria socioprofissional dos pais e o status de ocupação habitacional. Nossa hipótese é que a segregação entre os jovens das categorias populares e os das categorias superiores aumentou mais que aquela existente entre os adultos dessas categorias, em razão dos processos que acabamos de evocar; mas não temos uma hipótese nítida quanto à evolução da segregação entre os jovens das categorias populares e os das classes médias, pois os diferentes processos podem ter efeitos com sentido diverso. Não pudemos desenvolver análises que levem a especificar e verificar tais hipóteses por causa das dificuldades de acesso aos dados pormenorizados do novo censo. Esperamos concluir esse trabalho quando tais dificuldades se resolverem. Podemos, no entanto, como complemento dessa primeira análise da dimensão socioeconômica da segregação dos jovens, examinar, a partir de dados de que dispúnhamos sobre 1999, a dimensão etnorracial dessa segregação, assunto importante tanto por motivos teóricos - a taxa de fecundidade de grande parte das mulheres imigradas é mais elevada que a das mulheres não imigradas - quanto pela intensidade das discussões sociais em torno da questão 
das dificuldades de integração dos jovens de origem imigrada nos bairros populares.

\section{SEGREGAÇÃO ETNORRACIAL DOS JOVENS}

O termo raça não faz parte do vocabulário de categorização sociológica na França. Tal ausência resulta da recusa explícita de importar uma categoria ideológica que, sejam quais forem as circunvoluções intelectuais para afirmar seu caráter de constructo social, guarda sempre no cerne a afirmação de uma diferença biológica fundamentando diferenças culturais essenciais entre grupos e, na maioria de seus usos históricos, a afirmação de uma hierarquia entre esses grupos. Todavia, essa recusa de categorização sociológica em "raças" não consegue impedir o reconhecimento e a análise pelo sociólogo da existência de práticas e de representações racistas. Em matéria de segregação urbana, o reconhecimento de práticas de discriminação segundo a raça atribuída discriminação no acesso à moradia, no trabalho, na relação com as instituições públicas - justifica, a nosso ver, o uso do termo segregação etnorracial, visto ser ela resultante de tais discriminações.

Para apreender os grupos sujeitos a essas discriminações, o sistema estatístico francês dispõe de variáveis que, no censo e na maioria das grandes enquetes, especificam a origem nacional das pessoas (local de nascimento e nacionalidade, ou nacionalidade de origem para os franceses por aquisição). Tais variáveis permitem efetuar uma leitura "limitada" da etnicidade para detectar as discriminações sem ter de utilizar as categorias dos que discriminam ${ }^{5}$. Como os grupos que podem ser vítimas de discriminação etnorracial são hoje, na França, sobretudo os imigrados provenientes dos países magrebinos ou da África subsaariana, ou franceses nascidos nos departamentos e territórios ultramarinos das ilhas de Guadalupe ou Martinica, essas variáveis permitem caracterizá-los. Deixam de lado, porém, seus descendentes, que, embora não imigrados e franceses, na maioria dos casos podem ser igualmente discriminados em virtude da cor da pele, do nome, da religião real ou suposta etc. Quanto aos filhos de imigrados morando com os pais, é possível caracterizá-los por meio das variáveis de origem dos pais. Para os que já não pertencem ao domicílio parental, não é possível identificá-los nesse censo - mas o é em algumas pesquisas do INSEE ${ }^{6}$, que incluem a pergunta sobre a origem dos pais do entrevistado. Entretanto, até o censo de 1999, por causa do aspecto relativamente recente das vagas migratórias referentes a esses grupos, a maioria dos filhos - 
a chamada "segunda geração" - ainda era de jovens residindo com os pais (Borrel e Simon, 2005).

\section{Os Filhos dos Casais segundo a Origem dos Pais}

Já mostramos (Préteceille, 2009) que a segregação dos imigrados era sensivelmente superior à que seria resultante apenas das características socioprofissionais, o que tende a validar a ideia de segregação etnorracial. Também mostramos que, se essa segregação conheceu um ligeiro aumento na década de 1990, permaneceu bastante moderada para a maioria dos grupos de origem, cuja consequência era que a maioria dos imigrados residia em bairros onde os não imigrados eram maioria e só uma pequena minoria dos imigrados residia em bairros onde os imigrados eram maioria, ao contrário da ideia existente de que os imigrados viviam confinados em guetos. Serão esses resultados transponíveis para os filhos desses imigrados? ${ }^{7}$

Para responder a essa pergunta, cabe comparar, para 1999, os dados referentes à população dos imigrados segundo a origem nacional com os dados descrevendo a população dos filhos das famílias imigradas, definidas como famílias cuja pessoa de referência ou seu cônjuge são imigrados, categorizados de acordo com a origem nacional da pessoa de referência, se ela é imigrada, ou de seu cônjuge imigrado, se ela não o for $^{8}$. Trata-se, pois, da população dos filhos morando com os pais. $\mathrm{Na}$ ficha, não consta a idade desses filhos, mas é cabível pensar que a maioria deles está em idade escolar ou pré-escolar. Para 2007, os dados divulgados pelo INSEE permitem medir a distribuição por idade do conjunto de filhos das famílias (não se consegue distinguir os filhos das famílias imigradas), indicada na Tabela 1.

Tabela 1

Distribuição por Idade dos Filhos que Moram nos Domicílios

\begin{tabular}{l|c|c}
\hline \multicolumn{1}{c|}{ Idade } & $\mathbf{N}$ & \% \\
\hline 10 anos e menos & 1.648 .242 & 46,0 \\
11 a 17 anos & 971.776 & 27,1 \\
18 a 24 anos & 666.960 & 18,6 \\
25 a 39 anos & 242.572 & 6,8 \\
40 a 64 anos & 52.856 & 1,5 \\
65 anos e mais & 2.321 & 0,1 \\
\hline Total & $\mathbf{3 . 5 8 4 . 7 2 8}$ & $\mathbf{1 0 0 , 0}$ \\
\hline
\end{tabular}

Fonte: INSEE, Censo da População de 2007. 
Para o conjunto das famílias, vê-se que $73 \%$ dos filhos têm menos de 18 anos. Cabe pensar que a proporção é ainda maior para os filhos de imigrados, uma vez que a população de imigrados é mais jovem que a média. Esses resultados de 2007 devem ser muito parecidos com os de 1999. Os dados que analisamos se referem, portanto, aos jovens de famílias imigradas.

Para que o leitor possa avaliar o tamanho dos grupos em questão, na Tabela 2 estão os efetivos, tanto do conjunto de pessoas quanto dos filhos, por grupos de origem.

Tabela 2

Conjunto dos Indivíduos e Filhos que Moram nos Domicílios segundo a Origem Nacional em 1999

\begin{tabular}{l|c|c|c}
\hline \multicolumn{1}{c|}{ Origem } & $\begin{array}{c}\text { População dos } \\
\text { Indivíduos }\end{array}$ & $\begin{array}{c}\text { Filhos que Moram } \\
\text { nos Domicílios }\end{array}$ & $\begin{array}{c}\text { Filhos/População } \\
\mathbf{( \% )}\end{array}$ \\
\hline Franceses nascidos franceses & 7.021 .668 & 1.700 .527 & 24,2 \\
USA, Canadá, NZ, Austrália & 18.950 & 9.204 & 48,6 \\
Europa do Norte & 67.785 & 31.480 & 46,4 \\
Europa do Leste & 96.681 & 39.702 & 41,1 \\
Itália & 58.453 & 25.201 & 43,1 \\
Espanha & 54.077 & 25.616 & 47,4 \\
Portugal & 210.657 & 138.688 & 65,8 \\
Argélia & 202.157 & 178.117 & 88,1 \\
Tunísia & 78.390 & 75.079 & 95,8 \\
Marrocos & 152.087 & 133.527 & 87,8 \\
África subsaariana & 190.774 & 166.555 & 87,3 \\
Turquia & 45.330 & 33.387 & 73,7 \\
Oriente Médio & 49.462 & 33.147 & 67,0 \\
Índia, Paquistão & 56.815 & 42.793 & 75,3 \\
Ásia Leste e Sudeste & 123.186 & 72.521 & 58,9 \\
América Latina & 41.220 & 28.958 & 70,3 \\
Outros & 531 & 329 & 62,0 \\
\hline Total & $\mathbf{2 . 7 6 8 . 2 2 3}$ & & $\mathbf{3 2}$ \\
\hline
\end{tabular}

Fonte: INSEE, Censo da População de 1999.

O campo geográfico considerado é o do conjunto dos TRIRIS ${ }^{9}$ da região Ile-de-France, que tinha 10.951.136 habitantes em 1999. Logo, o campo estudado corresponde a $77 \%$ do total. Os espaços em branco são os dos 
pequenos municípios, sobretudo na periferia da aglomeração central da metrópole ${ }^{10}$.

Para todas as origens imigradas, a proporção entre o número de filhos das famílias e o número de imigrados (que inclui apenas os filhos que são imigrados ou estrangeiros, e não os nascidos franceses) é superior à dos franceses nascidos franceses e à média. A proporção das crianças é especialmente importante para os originários da Tunísia (quase três vezes a média), da Argélia, do Marrocos e da África subsaariana (2,7 vezes a média).

\section{As Diferenças de Distribuição Espacial: Índice de Dissimilitude}

Para estudar a intensidade dessa segregação, calculou-se primeiro para os filhos das famílias de cada um dos grupos de origem imigrada o índice de dissimilitude ${ }^{11}$ em relação aos filhos das famílias não imigradas, e ele foi comparado (Gráfico 1) com o dos imigrados em relação aos franceses nascidos franceses ${ }^{12}$. Convém lembrar que esse índice pode ser interpretado como a percentagem de um grupo que deveria mudar-se para ter a mesma distribuição residencial do segundo.

\section{Gráfico 1}

Índice de Dissimilitude entre Imigrados e Não Imigrados, para Indivíduos e Filhos que Moram nos Domicílios. TRIRIS Ile-de-France 1999

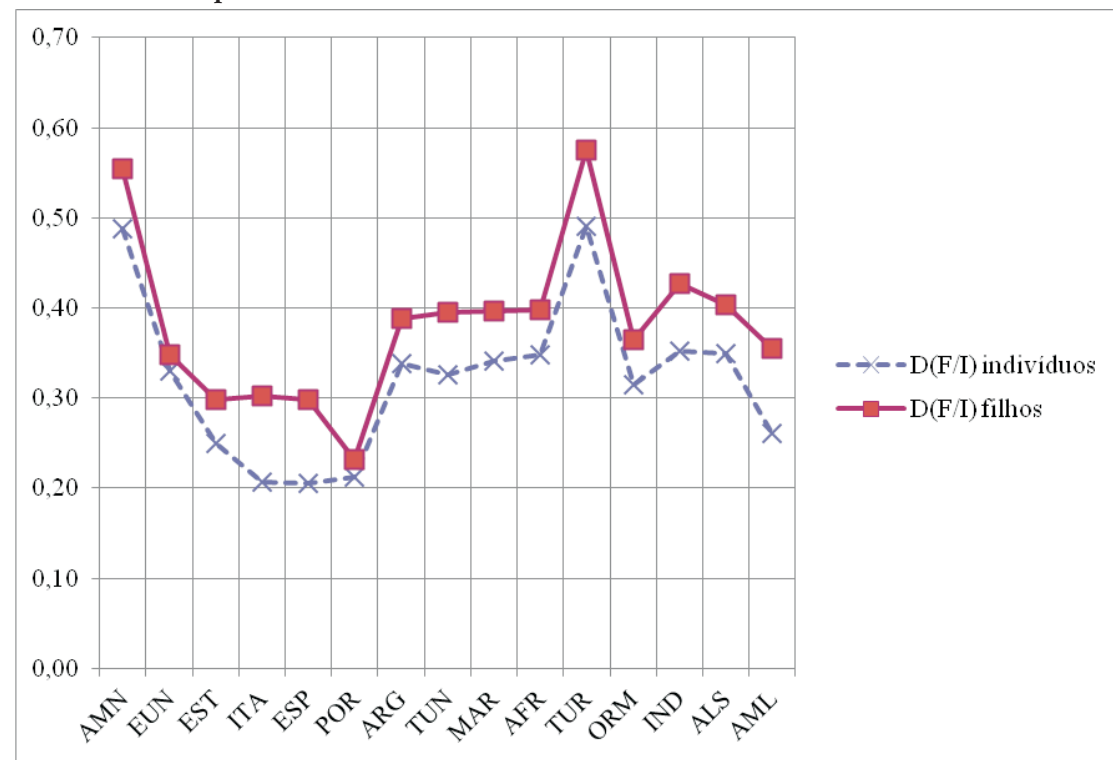

Fonte: INSEE, Censo da População de 1999. 
O acréscimo de segregação para os filhos de famílias imigradas é significativo: para as origens magrebinas (ARGélia, TUNísia, MARrocos) e subsaarianas (AFR), passa-se de cerca de 0,35 para cerca de 0,40 , ou seja, de $15 \%$ a $20 \%$ de aumento; e é de idêntica ordem de grandeza para todos os outros grupos. É sensivelmente mais forte para as origens italiana e espanhola, o que se explica visto que a maioria dos imigrados dessas origens é mais idosa, enquanto as famílias com filhos são mais jovens e apresentam outro perfil. Entretanto, a diferença é quase nula para os portugueses.

\section{As Diferenças de Contexto Social Local: Índice de Isolamento}

Comparou-se do mesmo modo o índice de isolamento dos filhos dessas famílias com o dos indivíduos dos mesmos grupos de origem (Gráfico 2). Lembremos que esse índice mede a probabilidade de os membros de um grupo só terem como vizinhos os membros do próprio grupo. Esse índice é, por definição, muito sensível ao tamanho do grupo.

\section{Gráfico 2}

Índice de Isolamento dos Imigrados e dos Filhos que Moram nos Domicílios de

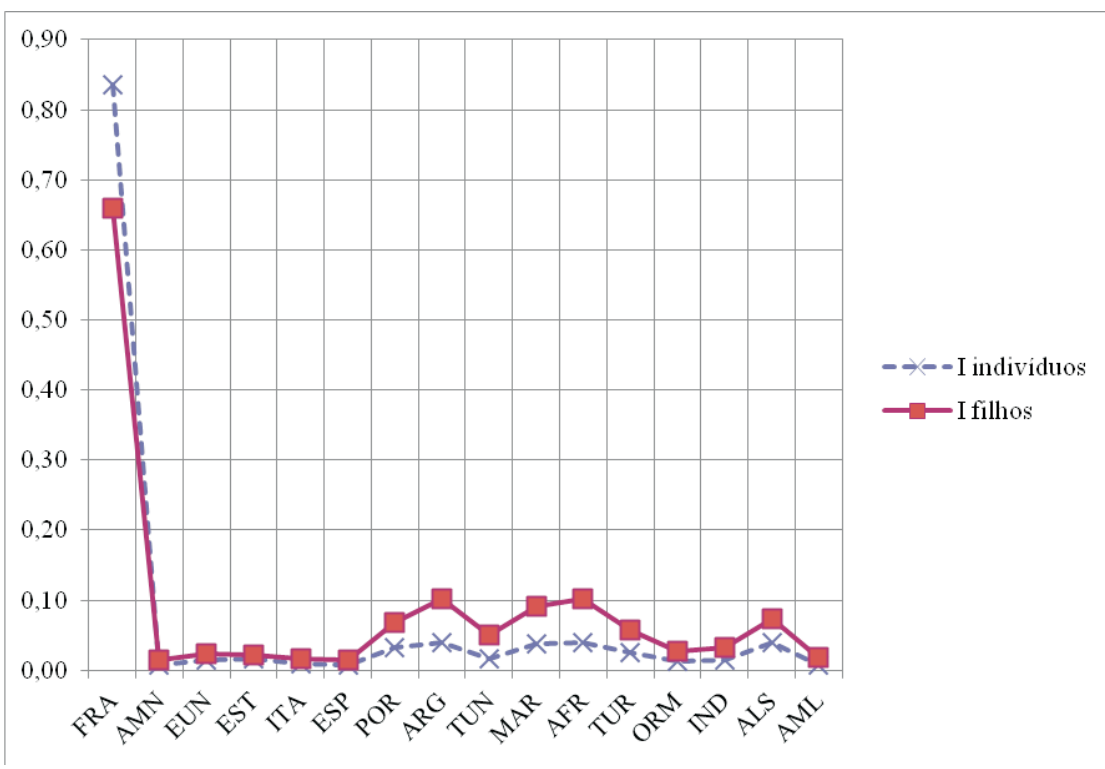

Fonte: INSEE, Censo da População de 1999. 
Logicamente, pelas diferenças de tamanho, e como a segregação dos grupos é moderada, o índice é bastante forte apenas para os não imigrados, sendo fraco para cada grupo imigrado.

É interessante notar que, para os não imigrados, o índice de isolamento dos filhos é inferior ao do grupo em seu conjunto - o que significa que os filhos de pais não imigrados estão mais propensos a encontrar, em seu bairro (TRIRIS) de residência, filhos de pais imigrados que o grupo a encontrar imigrados.

Ao contrário, para todas as origens imigradas, o índice de isolamento dos filhos é superior ao do grupo. É duas vezes maior para os de origem portuguesa; 2,4 vezes para os de origem marroquina; 2,6 vezes para os de origem argelina e subsaariana; e 2,4 vezes para os de origem indiana ou paquistanesa. Levando-se em conta que os grupos de filhos das famílias são de menor tamanho que o grupo imigrado de mesma origem, o que deveria a priori baixar o índice de isolamento dos filhos em relação ao do grupo, chega-se a um forte argumento que faz pensar em uma distribuição espacial nitidamente mais específica dos filhos.

Como o índice de isolamento é sensível ao tamanho dos grupos, e como se sabe que os imigrados de diferentes origens tendem a ter localizações residenciais bastante semelhantes (o que será verificado mais adiante para os filhos) na metrópole parisiense, e como a questão das discriminações atinge particularmente os imigrados provenientes do Magrebe, do Oriente Médio e da África subsaariana, calculou-se igualmente o índice de isolamento reagrupando essas origens. Encontra-se para o conjunto desse grupo imigrado um índice de isolamento de 0,127; para o grupo dos filhos das famílias dessas mesmas origens imigradas, um índice de 0,315 , ou seja, 2,5 vezes mais, o que é um valor bem inferior ao das minorias etnorraciais nas grandes cidades norte-americanas, mas que não pode ser desprezado.

\section{As Situações Locais de Forte Concentração}

Esses índices são calculados no conjunto das situações urbanas e fazem, por isso, uma média entre situações de maior ou menor mistura (mixité) residencial entre grupos diferentes. Sabe-se que uma parte da discussão concerne à existência ou não de "guetos de imigrados", e é preciso verificar essa existência ou não, bem como a frequência de situações de forte reagrupamento. Para tal, foram aqui reunidas as origens magrebinas, subsaarianas, médio-orientais e asiáticas. 


\section{Gráfico 3}

Parte dos Imigrados e dos Filhos que Moram nos

Domicílios de Famílias Imigradas.

TRIRIS Ile-de-France 1999

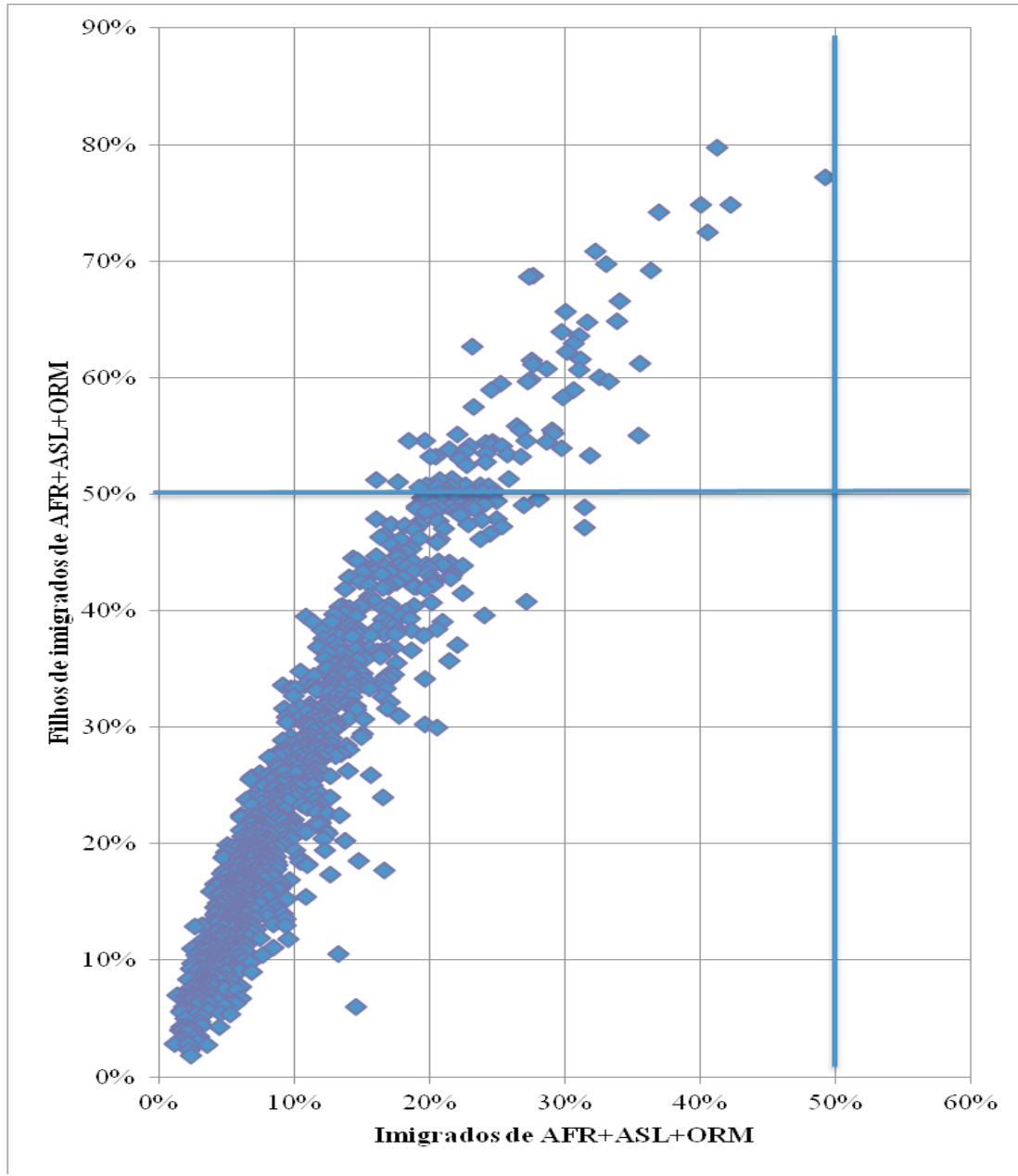

Fonte: INSEE, Censo da População de 1999.

O Gráfico 3 representa os TRIRIS segundo a proporção dos imigrados desse grupo na população local, em abscissa, e a proporção dos filhos das famílias dessas origens imigradas na população local dos filhos das famílias, em ordenada.

Vê-se que a correlação entre as duas distribuições é muito forte, o que não surpreende. Vê-se também que os níveis extremos de concentração 
são bem diferentes. Só havia 16 TRIRIS nos quais os imigrados dessas origens eram maioria em 1999. Para os filhos das famílias, o caso é outro, já que uma minoria não desprezível dos TRIRIS (82 em 1.126) apresenta uma proporção superior a 50\%, reagrupando $21 \%$ da população dos filhos das famílias dessas origens.

A Tabela 3 mostra a distribuição dos filhos de imigrados dessas origens conforme os graus de concentração local.

Tabela 3

Distribuição dos Filhos que Moram nos Domicílios de Famílias Imigradas de Origens Magrebina, Subsaariana, Médio-orientais e Asiáticas segundo seu Peso no TRIRIS de Residência em 1999

\begin{tabular}{l|c}
\hline Peso local & Efetivo \\
\hline$>50 \%$ & 157.005 \\
41 a 50\% & 144.485 \\
31 a 40\% & 150.977 \\
21 a 30\% & 134.978 \\
11 a 20\% & 122.471 \\
0 a 10\% & 25.210 \\
\hline Total & 735.126 \\
\hline
\end{tabular}

Fonte: INSEE, Censo da População de 1999.

Se a situação de mistura de grupos de origens diversas permanece, portanto, como a experiência da maioria (quase 80\%) dos filhos dessas origens, a parte dos que são localmente maioria não é desprezível.

Cabe salientar ainda que mais da metade, $61 \%$, reside em bairros (TRIRIS) onde constituem mais de $30 \%$ da população local dos filhos das famílias, ao passo que os imigrados que residem em bairros onde representam mais de $30 \%$ da população local são nitidamente minoria.

O Mapa 2 indica a distribuição espacial dos TRIRIS em função da proporção local dos filhos com essas origens.

Não é possível comparar diretamente esse mapa com o primeiro, que dava a distribuição do conjunto dos filhos das famílias, porque há uma diferença de escala das unidades espaciais (a primeira era no IRIS, essa é no TRIRIS), além da ausência de dados para os pequenos municípios, muito numerosos no segundo anel da periferia. Sabe-se, porém, que os imigrados estão nitidamente sub-representados em média nesses pe- 
Distribuição Espacial dos Filhos que Moram nos Domicílios de Famílias Imigradas na Metrópole Parisiense

TRIRIS 1999

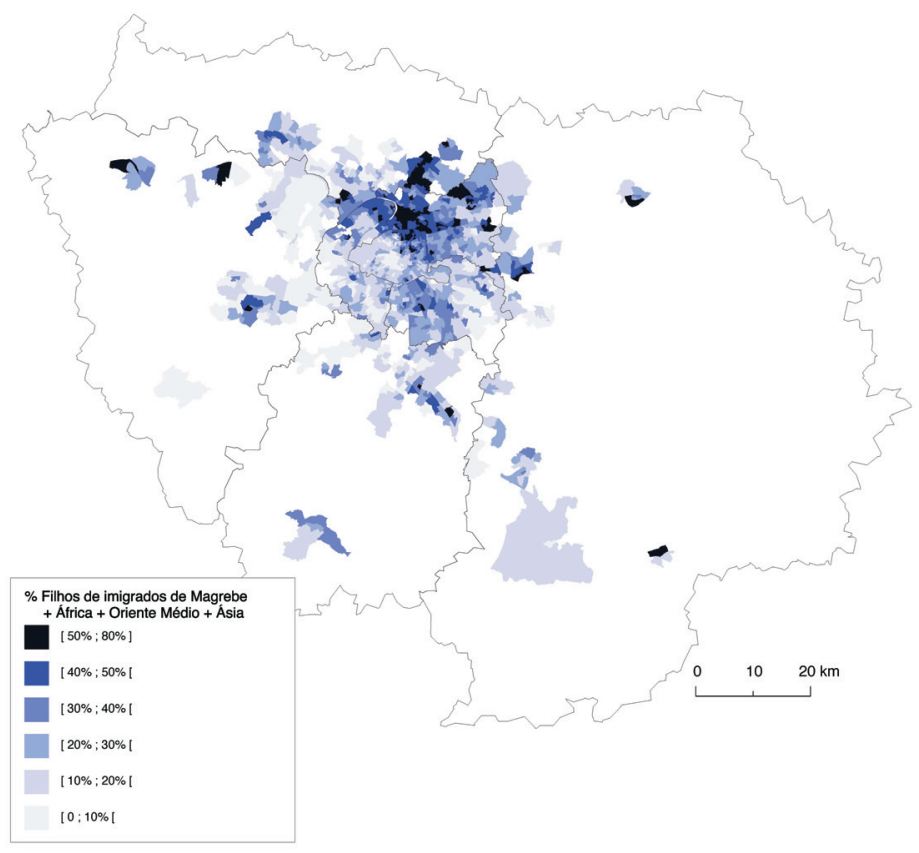

Fonte: INSEE, Censo da População de 1999.

quenos municípios: em 2007, no conjunto dos IRIS não pertencentes a um TRIRIS e que são ou pertencem a municípios demasiado pequenos para serem divididos em TRIRIS, encontra-se $20 \%$ da população total da região, mas apenas $10 \%$ dos imigrados. Logo, as famílias imigradas de origens magrebinas, subsaarianas, médio-orientais e asiáticas estão em média pouco presentes nesses pequenos municípios. Há assim um contraste entre as distribuições espaciais dos filhos das famílias não imigradas, que estão presentes em todas as áreas do segundo anel, e as dessas famílias imigradas, que só têm forte presença na parte exterior do segundo anel em certo número de TRIRIS que correspondem a grandes conjuntos habitacionais de aglomerações periféricas (a oeste, 
no departamento de Yvelines, Mantes-la-Jolie, Les Mureaux e Trappes; a leste, no departamento de Seine-et-Marne, Meaux e Montereau). Os bairros com maior concentração desses filhos de famílias imigradas são nitidamente mais centrais, e a maioria se encontra em um triângulo cujo vértice sudoeste fica no distrito XIX de Paris, o vértice sudeste em Clichy-sous-Bois e Montfermeil, a leste do departamento de SeineSaint-Denis, e o vértice norte em Villiers-le-Bel ou Goussainville, ao sul de Val-d'Oise.

A oeste da aglomeração central, os bairros com forte concentração de filhos dos imigrados são menos numerosos; encontram-se em Argenteuil, Gennevilliers e Nanterre; ao sul, em Vitry, Grigny e CorbeilEssonnes; a leste, em Bagnolet, Noisy-le-Grand e Lognes.

\section{Tipologia dos Espaços Residenciais dos Filhos das Famílias segundo a Origem}

Para verificar se seria encontrado para os filhos das famílias o resultado evocado anteriormente para os imigrados, de acordo com o qual os bairros de forte concentração de imigrados reúnem os imigrados de diferentes origens (com exceção daqueles vindos dos Estados Unidos ou da Europa do Norte, que ficam nos melhores bairros), foi construída uma tipologia dos TRIRIS em função da distribuição dos filhos das famílias segundo os grupos de origem dos pais. Não é aqui apresentada em pormenor essa tipologia, o que excederia os limites deste artigo, mas serão apenas indicados, na Tabela 4 , os perfis dos dez tipos conforme a densidade relativa das diferentes categorias de origem (média $=$ 100).

Destacam-se quatro resultados.

a) Encontra-se o resultado obtido considerando apenas o total dos filhos de imigrados não europeus ou norte-americanos; dos dez tipos obtidos, cinco (F, G, H, I e J) caracterizam-se por uma proporção de filhos das famílias (FRA) não imigrados inferior à média e concernem a $36 \%$ do total dos filhos e a $53 \%$ dos filhos de imigrados não europeus ou norte-americanos.

b) Nesses cinco tipos, como nos outros que têm uma presença inferior à média, mas notável, dos filhos dessas mesmas origens, encontra-se de fato uma presença significativa dos diferentes grupos de origem. Quando um grupo de origens está super-representado, quase todos os 
Edmond Préteceille

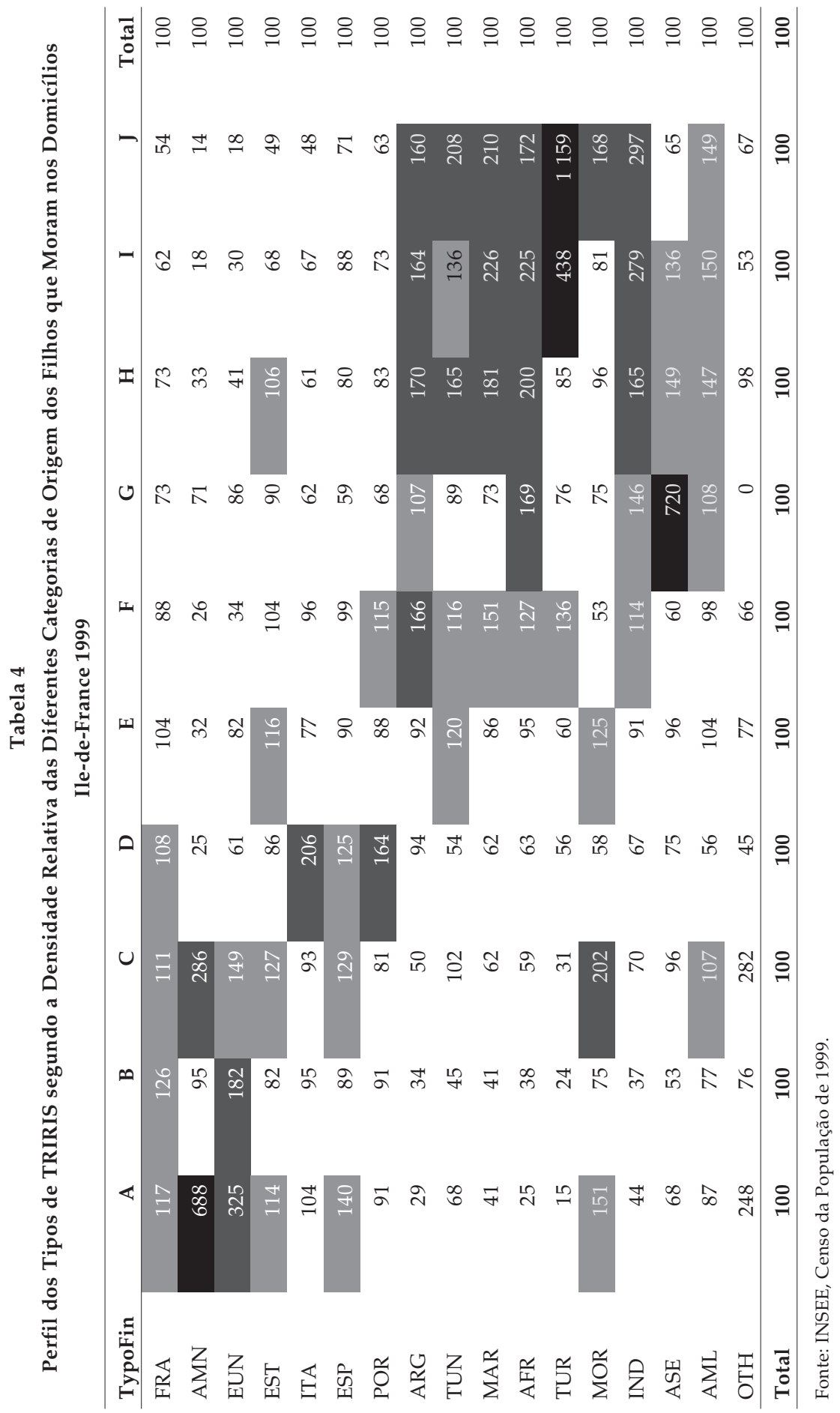


outros também estão; encontra-se o resultado obtido para o conjunto dos imigrados, que é essa mistura residencial das origens, tão diferente do mosaico urbano dos Estados Unidos, no qual cada grupo tem seus bairros de reagrupamento quase exclusivo - mesmo que existam bairros com tal mistura (Logan e Zhang (2010) e Logan (2011).

c) Dois grupos se distinguem, porém, pela fortíssima super-representação em certos tipos apenas: os filhos das famílias imigradas provenientes da Ásia do Leste ou do Sudeste, no tipo G - presença sete vezes superior à média; os filhos das famílias imigradas originárias da Turquia, no tipo I - presença quatro vezes superior à média; e o tipo J onze vezes. Essa forte super-representação não invalida, contudo, o resultado anterior, pois, mesmo nesses espaços em que os filhos de origem asiática ou turca estão muito super-representados, permanecem minoritários se comparados aos filhos de outras origens imigradas.

d) Os filhos de origem turca formam um caso à parte; mais de $40 \%$ deles residem nos dois tipos nos quais estão fortemente super-representados. Para os filhos, é ainda mais acentuada a singularidade já constatada para a segregação dos imigrados de origem turca, grupo cujo nível de segregação era o mais elevado em 1999 e único cuja segregação havia nitidamente aumentado entre 1990 e 1999 (Préteceille, 2009) ${ }^{13}$.

\section{CONCLUSÃO}

Os jovens, que são mais dependentes dos recursos urbanos locais e das condições de sociabilidade local, são os mais atingidos pelas desigualdades urbanas por causa da localização mais periférica dos pais. Já o são $a$ priori por pertencerem às categorias sociais mais populares, exceto para aqueles que residem em conjuntos habitacionais dos quais boa parte fica em Paris ou na periferia mais próxima. Para as classes médias, que têm pouco ou nenhum acesso à habitação social, seus recursos já não lhes permitem aceder às zonas centrais. Para a fração das classes populares estáveis que pode aceder à propriedade, esse acesso tem um preço: a localização nas partes menos equipadas da metrópole. Só os jovens das categorias superiores têm, tendencialmente, acesso ao alto nível de equipamentos escolares do núcleo da metrópole.

Tais diferenças segundo o nível socioeconômico se juntam às diferenças aparentes entre filhos das famílias de acordo com a origem, imigrada ou não, e as nacionalidades de origem dos pais. Se a segregação dos imigrados é relativamente moderada e permaneceu estável durante a 
década de 1990, a dos filhos das famílias de origem não europeia ou norte-americana é sensivelmente mais acentuada. Era ainda moderada, mas em nível mais elevado, em 1999, exceto para as crianças de origem turca, para as quais a segregação era bastante forte, com um índice de dissimilitude superior a 0,5 .

Essa segregação sensivelmente mais acentuada resulta de uma forte concentração de crianças nas zonas em que a presença dos imigrados é maior. Mais de 20\% dos filhos de famílias originárias do Magrebe, da África, do Oriente Médio ou da Ásia residia, em 1999, em bairros onde eles eram maioria entre as crianças. Para essa porção, certamente minoritária, mas não desprezível, isso significa condições mais difíceis de integração na sociedade francesa por três motivos.

Por um lado, essa composição da população local dos filhos se traduz diretamente na composição da população escolar, com escolas em que a maioria dos alunos é de origem imigrada. A explicação habitual para isso é que os pais não imigrados evitam esses estabelecimentos; de fato, é antes de tudo o reflexo da estrutura local da população escolarizável, ao passo que essa prática do evitar é reduzida nos meios populares. É correto pensar que essa forte segregação escolar se traduz por dificuldades escolares ainda maiores para as crianças desses bairros, como Felouzis (2003) mostrou para os colégios mais segregados da metrópole de Bordeaux.

Por outro lado, o grupo de pares no bairro também é formado de filhos de imigrados, o que provoca decerto muitos efeitos de socialização específicos, que reforçam a coesão do grupo local - cultura dos bandos de jovem, atitudes físicas, culto da força e da "luta" entre os meninos, dominação das meninas, afirmação de religiosidade muçulmana buscando derrubar o estigma por uma requalificação simbólica (Kakpo, 2007), "linguagem de subúrbio" (Lepoutre, 1997) etc. -, mas dificultam a integração social mais geral na escola, nas relações com os empregadores e com as instituições públicas.

Enfim, os bairros que aparecem como lugares de concentração elevada são, quase sempre, bairros situados nos espaços de subúrbio mais marcados pela precariedade, pelo desemprego e pela pobreza, dificuldades que qualificam as precedentes e se agregam a elas. Para essa minoria não desprezível de filhos de imigrados, tais condições de difícil experiência urbana combinadas com as de sociabilidade local reforçam a desigualdade de oportunidades, que se acumulam como obstáculos 
que levam forçosamente a preparar difíceis condições de vida para a sua idade adulta.

Os resultados aqui apresentados ainda são parciais e insatisfatórios metodologicamente. Esperamos que as providências tomadas permitam o acesso a dados mais elaborados e recentes, a fim de responder a essas questões de maneira completa e consistente. Por um lado, a escala espacial que pudemos estudar, a dos TRIRIS, bairros com cerca de 8.000 habitantes, talvez mascare segregações ainda mais fortes segundo a escala mais apurada dos IRIS, que correspondem melhor ao bairro da experiência cotidiana dos jovens. Por outro lado, será preciso especificar aquilo que, nessas segregações e em seus efeitos, decorre de causalidade socioeconômica e o que decorre de discriminações etnorraciais, visto que só pudemos analisar essas dimensões separadamente.

Seria também preciso analisar de modo mais apurado as situações e as evoluções sobre essas duas dimensões nos diferentes tipos de espaço da metrópole, e não apenas nos mais pobres; os espaços mais comuns, que qualificamos de "médios-mistos" são importantes porque se pode propor a hipótese de que, para muitos, a coesão social se estabelece e se desenvolve nesses espaços de mistura social realizada.

Em suma, é preciso analisar as evoluções em nosso período mais recente, pois as condições de conjunto da primeira década do século XXI na França são duplamente preocupantes, por causa do aumento da desigualdade social que se acelerou com a crise financeira e econômica mundial, e também pelo agravamento das discriminações etnorraciais incentivadas por elites políticas que tentam avivar o racismo e a xenofobia, até mesmo nas práticas de instituições públicas como a polícia, no intuito de obter benefícios eleitorais na competição com a extrema direita.

(Recebido para publicação em setembro de 2011)

(Aprovado para publicação em março de 2012) 


\section{NOTAS}

1. A metrópole no sentido socieconômico é apreendida estatisticamente pelo INSEE (Institut National de la Statistique et des Études Économiques) como categoria de área urbana: http://www.insee.fr/fr/methodes/default.asp?page=definitions / aire-urbaine.htm. Utilizamos aqui, por motivo de acesso aos dados, uma definição um pouco mais restritiva, que é a da parte urbana da região Ile-de-France, ver mais adiante.

2. Se a municipalidade de Paris, dirigida pela esquerda, deseja desenvolver a habitação social, o mesmo não ocorre com as municipalidades de direita de Hauts-de-Seine, como Neuilly-sur-Seine, que não têm esse desejo.

3. Embora a área urbana de Paris ultrapasse a região desde 1999, Ile-de-France contém o essencial. Essa região é o primeiro nível infranacional de governo local; o segundo é o departamento; o terceiro, a municipalidade. A região Ile-de-France tem oito departamentos: Paris, no centro (que é ao mesmo tempo departamento e municipalidade); um primeiro anel ao redor de Paris, com os departamentos de Hauts-de-Seine a oeste, Seine-Saint-Denis a nordeste e Val-de-Marne a sudeste; um segundo anel, com os departamentos de Yvelines a oeste, Essonne ao sul, Seine-et-Marne a leste e Val-d'Oise ao norte.

4. Fonte: Indice des Notaires (Índice dos Tabeliães) - INSEE, série longa http:/ / www.insee.fr/fr/indicateurs/ind96/20110908/sl.xls

5. Para uma apresentação da discussão sobre as chamadas "estatísticas étnicas" e uma análise das práticas e das dificuldades da estatística pública na França sobre o assunto, ver Héran et alii (2010).

6. O INSEE é o principal organismo responsável pela produção das estatísticas públicas na França, equivalente ao IBGE (Instituto Brasileiro de Geografia e Estatística).

7. Para discutir o sentido desse termo no contexto francês e os problemas de escolha de categorias adequadas à análise da segregação em um país em que a categoria de raça está excluída do sistema estatístico, cf. Préteceille (2009:492-495).

8. Tabulação especial do recenseamento de 1999 obtida por meio da rede Quételet; definição do quadro realizada com a ajuda de A. Kych, ADISP-CMH.

9. Os TRIRIS são reagrupamentos de três IRIS; IRIS (Setores Censitários Reagrupados para Informação Estatística) são áreas com cerca de 2.000 pessoas, definidos pelo INSEE. Os TRIRIS são um pouco menores ( 8.000 habitantes em média) que as áreas de ponderação definidas pelo IBGE para o censo brasileiro.

10. Restrição decorrente do modo como o INSEE aplica as regras da Comissão Nacional de Informática e Liberdades, que proíbem a difusão dos dados sobre as nacionalidades, chamadas variáveis sensíveis, referentes a unidades com menos de 5.000 habitantes. Isso leva a subestimar a segregação dos imigrados, que estão pouco presentes nessas comunas periurbanas, sem que se possa afirmar se, por isso, a de seus filhos é mais ou menos subestimada.

11. Índice mais utilizado para medir a segregação pela diferença das distribuições. Ver Duncan e Duncan (1955), na apresentação da 1a ed., e Massey e Denton (1988) para uma discussão dos diferentes tipos de índice. 
12. Os valores são diferentes dos que publicamos anteriormente (Préteceille, 2009) porque não só a escala do recorte espacial é aqui a dos TRIRIS mas também porque não distinguimos os franceses nascidos franceses na metrópole daqueles nascidos nos DOM-TOM, o que não pode ser feito com os filhos das famílias.

13. A discussão dessa singularidade referente aos imigrados turcos nos levaria além dos limites deste artigo, sobretudo porque, para a metrópole parisiense, enquetes localizadas mostram que esse grupo é heterogêneo, uma vez que essa mesma origem nacional compreende imigrados de origem turca propriamente dita, de língua turca e de tradição muçulmana, mas também imigrados de origem curda, e ainda outros de origem caldeia que são cristãos; esses três grupos têm relações historicamente conflituosas decorrentes da dominação muitas vezes violenta do primeiro sobre os outros dois.

\section{REFERÊNCIAS BIBLIOGRÁFICAS}

BONVALET, Catherine (ed.). (1994), Logement, Mobilité et Populations Urbaines. Paris, CNRS.

BORREL, Catherine e SIMON, Patrick. (2005), “Les Origines des Français”, in C. Lefèvre e A. Filhon (eds.), Histoires de Famille, Histoire Familiale. Les Résultats de l'Enquête Famille en 1999. Paris, INED, pp. 425-441.

DESROSIÈRES, Alain e THÉVENOT, Laurent. (1988), Les Catégories Socio-professionnelles. Paris, Editions La Découverte.

DUNCAN, Otis Dudley e DUNCAN Beverley. (1955), “A Methodological Analysis of Segregation Indexes". American Sociological Review, vol. 20, pp. 210-217.

FELOUZIS, Georges. (2003), “La Ségrégation Ethnique au Collège et ses Conséquences”. Revue Française de Sociologie, vol. 44, no 3, pp. 413-447.

HÉRAN, François et alii. (2010), “Inégalités et Discriminations. Pour un Usage Critique et Responsable de l'outil Statistique. Rapport du Comité pour la Mesure de la Diversité et l'Évaluation des Discriminations. Disponível em http://www.gouvernement.fr/sites/default/files/fichiers_joints/Rapport_COMEDD_.pdf.

KAKPO, Nathalie. (2007), L'Islam, un Recours pour les Jeunes. Paris, Presses de Sciences Po.

KOKOREFF, Michel. (1996), “Jeunes et Espaces Urbains. Bilan des Recherches en France, 1977-1994". Sociologie et Sociétés, vol. 28, no 1, pp. 159-176.

LAPEYRONNIE, Didier. (2008), Ghetto Urbain. Ségrégation, Violence, Pauvreté en France Aujourd'hui. Paris, Robert Laffont.

LE BRAS, Hervé e CHESNAIS, Jean-Claude. (1976), “Cycle de l'Habitat et Âge des Habitants". Population, no 2, pp. 269-298. 


\section{Edmond Préteceille}

LEPOUTRE, David. (1997), Cour de Banlieue. Codes, Rites et Langages. Paris, Odile Jacob.

LOGAN, John e ZHANG, Charles. (2010), “Global Neighborhoods: New Pathways to Diversity and Separation". American Journal of Sociology, vol. 115, no 4, pp. 1069-1109.

LOGAN, John. (2011), “Separate and Unequal: The Neighborhood Gap for Blacks, Hispanics and Asians in Metropolitan America". US2010 Project, Providence, Brown University. Disponível em http://www.s4.brown.edu/us2010/Data/Report/report0727.pdf.

MASSEY, Douglas S. e DENTON, Nancy A. (1988) , "The Dimensions of Residential Segregation". Social Forces, vol. 67, no 2, pp. 281-315.

OBERTI, Marco. (2007), L'École dans la Ville. Ségrégation - Mixité - Carte Scolaire. Paris, Presses de Sciences Po.

PRÉTECEILLE, Edmond. (2001), Division Sociale et Services Urbains. Les Inégalités d'Équipement entre Communes Urbaines d'Ile-de-France. Paris, Cultures et Sociétés Urbaines. Vol. II.

. (2003), La Division Sociale de l'Espace Francilien. Typologie Socioprofessionnelle 1999 et Transformations de l'Espace Résidentiel 1990-99. Paris, Observatoire Sociologique du Changement Sciences Po-CNRS. Disponível em http://osc.sciencespo.fr/equipe/popup/DivSocIdF99.pdf.

. (2006), “La Ségrégation Sociale a-t-elle Augmenté? La Métropole Parisienne entre Polarisation et Mixité". Sociétés Contemporaines, no 62, pp. 69-93.

. (2009), “La Ségrégation Ethno-raciale a-t-elle Augmenté dans la Métropole Parisienne?". Revue Française de Sociologie, vol. 50, no 3, pp. 489-519.

VAN ZANTEN, Agnès. (2009), Choisir son École. Paris, Presses Universitaires de France. 


\section{ABSTRACT}

Youth Segregation in Paris

Daily life, especially for youth, is closely related to place of residence, and urban segregation thus has important consequences for young people. However, their segregation is not identical to that of the general population, given the peculiar characteristics of families with children; youth segregation thus deserves to be analyzed. This article reports on a case study of youth in Paris. The first part examines socioeconomic segregation, which tends to exclude young people of more modest origins from access to urban resources, nearly always concentrated in the central areas of the metropolis; social housing compensates for the centrifugal trend for some of these youth, but this trend is increasingly accentuated in the middle classes. The second part discusses ethnic/racial segregation based on the national origins of their families; young people's own segregation is more striking than that of immigrants themselves, and a significant minority of immigrant-descendant youth lives in neighborhoods where they are the majority within the young population as a whole.

Key words: segregation; youth; Paris

\section{RÉSUMÉ}

\section{La Ségrégation des Jeunes à Paris}

Parce que leur vie quotidienne est fortement inscrite dans leur quartier de résidence, la ségrégation urbaine a des conséquences plus particulièrement importantes pour les jeunes. Mais la ségrégation des jeunes diffère de celle de la population générale du fait des caractéristiques particulières des ménages avec enfants, et doit donc être analysée comme telle. L'article étudie le cas des jeunes dans la métropole parisienne. Dans la première partie, on s'intéresse à la ségrégation socio-économique; celle-ci tend à éloigner les jeunes des ressources urbaines qui sont particulièrement concentrées dans les zones centrales de la métropole, d'autant plus qu'ils sont de milieux plus populaires ; le logement social compense pour une partie de ces derniers les tendances centrifuges; mais celles-ci sont de plus en plus marquées pour les classes moyennes aussi. Dans la seconde partie, on discute la ségrégation ethno-raciale, étudiée à partir des origines nationales des ménages auxquels appartiennent les jeunes; on montre qu'elle est plus marquée que celle des immigrés eux-mêmes, et qu'une minorité non négligeable des jeunes d'origine immigrée réside dans des quartiers où ils sont majoritaires parmi les jeunes.

Mots-clés: ségrégation; jeunes; Paris 